\title{
Rationality and Bounded Rationality in Decision Making
}

\author{
Mundhir AL Hasani, PhD Candidate \\ Bond University, Faculty of Society \& Design, Queensland, Australia
}

Doi: 10.19044/elp.v6no1a2

URL:http://dx.doi.org/10.19044/elp.v6no1a2

\begin{abstract}
Every day people are faced with decisions because of the various issues that are inevitable in day-to-day life. In the same breath, during the choices, there is numerous information on a given phenomenon; information that cannot be comprehended in full and used in making the decisions. This paper seeks to look at the limitations of the market and how they have influences on the different choices that humans make. Moreover, the first part of the paper will address behaviour science and the concept of bounded rationality. The next phase will offer a theoretical glimpse and by so doing compare rationality theory and the critique offered through bounded rationality. Based on the above understanding the paper will then go into detail and look at different concepts related to the subject matters of this paper. The concepts will be decision making in times of uncertainty and risk, the responses of humans when faced with different alternatives and what shapes the choices and how they are shaped.
\end{abstract}

Keywords: Rationality, decision making, bounded rationality, risk and uncertainty.

\section{Introduction}

The limitations that cloud individuals while tackling uncertainties and must make certain rational choices is well spelt out in bounded rationality. Bounded rationality refers to the different constraints that normally impede decision making. They come in various forms most notably cognitive limitations, time available and other environmental factors. Herbert Simon is considered as the pioneer of this school of thought. Bounded rationality views rationality as being because of the need for satisfaction as opposed to optimisation. In this regard, unlike in the case of optimisation, rationality is hinged on the availability of simple choices that are used to make the most satisfactory choices and options other than the most optimal choice. The constraints come in different forms and have an impact on the rational choices 
that are made to counter the challenges. This paper affirms that the operating environment and human reactions to the environment have an impact on the rationality of decision making.

Additionally, bounded rationality aims to set a limit to some assumptions associated with economics and at the same time explain how one's behaviour is influenced by important factors. Particularly, one's judgement is influenced by personality, the capability to think rationally, knowledge, one's access to needed information and one's biases and prejudices. This only indicates that economics assumes that humans always act or come up with a rational decision for self-interest. Bounded rationality asserts that such an assumption is not always correct as different factors may influence one's willingness to take the risk, decide on various issues such as insurance, prepare financial forecasts and make a wild guess at the future.

\section{Behavioural Science and Bounded Rationality}

Bendor (2010) views bounded rationality as a function of human behaviour and look at the way people make rational decisions during uncertainties. The pioneers of economic including Adam Smith, considered as the father of economics, while making their points noted that a man is economical and normally makes certain decisions because of self-interest motivation. The decisions are made about all things that touch on the lives of people. In that regard, while making decisions regarding other people or property, people would only look at what they stand to gain in those circumstances (Pack \& Schliesser, 2018).

As Eusepi and Hamlin (2006) and Vlaev (2018) noted bounded rationality narrows down the different things that are assumed to influence the behaviour of people. Faced with uncertainties and decision making, people normally make a decision based on their personality, and this may be either their level of optimism or negativism. On the same note, decisions are made by the available knowledge on the matter, logic, individual biases and stereotype and other personal understandings on the given matter. The whole point is that the decisions are normally hinged on the available information on the matter and as such is limited to the available know-how on the given phenomenon under scrutiny. In a nutshell, an economic man normally makes rational decisions that are biased toward self-interest. Bounded rationality, therefore, argues that there normally exists no justification as well as any different considerations that affect people's tendencies to incur the risk, make decisions on insurance and make economic predictions about the expectations.

Farina et al. (2006) says that full rationality implies the possession of unlimited cognitive abilities; something that is not common to humanity. Human beings are different and have limited cognitive abilities. This explains why Bayesian maximisation subjectivity is valid in explaining utility. 
However, even, with the Bayesian explanations, there is a tendency for deviation amongst many consumers, and this explains why some quarters fail to use the theorem and stick fully to it while making choices and decisions.

About rationality, there is a possibility of one knowing that a certain choice is the only rational one and still fail to take it. For example, one may believe that stopping smoking is the best thing to do and yet fail to stop smoking. This means that the conclusions made may be surpassed by strong emotional urges. The inability to have full control over behaviour is overridden by behaviour constraints rather than cognitive constraints.

According to He et al. (2014) and Kahneman (2003a, 2003b), bounded rationality refers to rationality that is pegged on the non-optimizing adaptive behaviour of real humans. It, however, does not refer to irrationality. Most of the time, human behaviour is not based on any conscious considerations, and this explains why people may not have to deliberate on which foot to place first while walking.

Phillips and Pohl (2014) note it is axiomatic that biological and cultural factors have a big role in human behaviour. As construed by its pioneers, people are only partly rational and have a big part which is irrational. This means that people normally have limitations while making the right choices to solve different challenges that may arise. In that regard, the economic cost involved in the acquisition of real information and processing it may inhibit the potential of people while making numerous choices and decisions. Simon suggested that people normally employ heuristics while making decisions. The use of heuristic is justified by the inability of people to know the outcome and the potential utility of all the available choices.

\section{Rationality Theory Vs Bounded Rationality Theory}

According to Gigerenzer and Gaissmaier (2011), rationality theory affirms the essence of economics as a subject since it forms the basis through which different economic principles are based. It argues that the economic man normally makes decisions that are realistic and logical and that such decisions are made on matters that would offer the individual the greatest utility. Moreover, individuals normally make those decisions with their selfinterest as a key point. The rational theory is a fundamental principle that most economic concepts and understanding are based on.

As noted by Weyland (2006) Hebert Simon through the theory of bounded rationality argued that people might have a desire to get all the relevant information on a given phenomenon before making decisions, but that is not normally the case. As such, people end up making decisions on limited know how on given phenomenon. On the same note, Richard Thaler through mental accounting proved that in some cases, people behave irrationally, and that is evident in their preference for certain dollars over others. 
As noted by Vlaev (2018) the through bounded rationality concept, it is evident that it is not realistic for people to have all the information and process it before making choices. In that regard, people devise means of coping and choosing certain things. For example, they have practice, methods and standard operating procedure (SOP) that help in the process of picking alternatives to make decisions. An example of habit/process is making the bed in the morning after waking up. Reading news on available products before making purchases is an example of method or technique. SOP could be represented by rules governing the interaction of different individuals in an organisation.

Bounded rationality postulates that even if people were given all the information about a given phenomenon, they would not be able to act on all the information and use them in making choices. In this regard, to predict the likely approach that would be used to make a decision, it would not be enough to know the quality of data used, but rather the cognitive approach used.

In this view decision making as presented by the bounded rationality principle implies that people are influenced by their operating environment. On the same note, they react given the situation they face within their environment, and their reactions determine the rationality they apply to a given matter and, by extension, the decision-making process.

The same theory affirms why people are likely to give different responses and thoughts on certain issues due to their different conception and internalisation of the facts of the case. While making decisions, errors may arise because the decisions so given would hinge on the understanding of people. On the same note, they would only go for those choices that would give them the best satisfaction. While picking the different choices, people normally have a bias by self-satisfaction Vlaev (2018).

\section{Nature of the Environment}

It is suggested by the supporters of limited rationality that primarily environment is highly uncertain than comprehended in prevailing choice models. Regarding rational choice models, uncertainty is described as unaware of the possibility of the consequences of decisions. Various illstructured problems exist within limited-rationality models, in which high uncertainty arises due to the presence of inadequate knowledge of the features illustrating the problem. This also incorporates ambiguity which has two meanings. Firstly, it includes those states in which attribute are clear, but not their comparative significance. Secondly, a major ambiguity involves those unclear alternatives which offer several meanings, having opposite explanations (Smithson, 2015; Walker et al., 2017). Resultantly, an ambiguous and uncertain environment affects the characteristics of the decision maker. It must not be forgotten that the desired end state is the outcome of preferences. 
Rationally, people set the highest possibility of achieving the desired end state; however, if it appears ambiguous, then preferences would be ambiguous also. This eventually contradicts the basis of rational choice, i.e. fixed transitive preferences (Wu et al., 2017).

People prefer to make decisions through mutual interaction, by employing decision strategies proposed by them. Thus, they must perform modification of the goals based on the social environment in which they exist. It is also proposed by various political analysts who claim that preferences are not static, but dynamic, and thus must be flexible to cope with changing environments (Bloom, 2014). It is a common practice that decisions exist in difficult ends-means causal chains. While finding a solution, we look toward new opportunities by excluding the irrelevant or undesired options. In short, the on-going process of problem-solving is based on interacting with the environment under dynamic constraints and opportunities.

\section{Decision Making Under Risk and Uncertainty}

Giang (2015) say decision making refers to the mental, cognitive processes that give rise to the selection of a certain choice during others in each circumstance or circumstances. It is common to experience inconsistency while choosing between or among many different alternatives. The above reality could also mar the anticipation of future events. There are various explanations for that background, as shall be elaborated upon in this section. There are cultural influences and the emotional state of the mind that may alter understanding. There could also be group thinking such as peer pressure. On the same note education and understanding of various issues may change over time and influence decisions and choices made.

In other cases, some people may be overconfident while others rely on a certain understanding and information while making their decisions. Others, still, may reject the views and opinions given by other people. In other instances, people make decisions based on the advice given to them by an adviser who may give information based on what the recipients would love to hear. Koleczko (2012) points out that in certain market conditions, trading may be influenced by automated trading systems which may in turn influence the decision-making process. The risk is a big player while making a decision, but its dynamic attribute normally influences decision making. This means that decisions about the future may be altered since the risks involved may change during time, and that may necessitate real valuation of the mitigating factors put in place to counter the expected risks in business.

Giang (2015) argues that businesses usually face different types of risks as discussed in this section. The first type of risk is legal risks. This type of risk refers to those risks that are related to the compliance level that a given business has about the prevailing laws that govern the operation of those kinds 
of business within the region. Strategic risks refer to the strategic realignment that a business would put in place to counter the competition that may arise within the industry under which a given business operates. Operational risks that refer to the types of risks that a business may face during operations are also imminent in the daily operation of a business. A business may also face financial risks. These types of risks account for the potential losses that may occur a business in its books of accounts. They, for example, imply the risks that are associated with investment decisions, risk on interest as well as risks incurred during daily operations of the financial capacity of the business.

Organisations must quantify the risks by the impact they may have on the business. In this regard, the cost implications of the risks must be tabulated to get the cost that the organisation may incur if the risks strike the organisation. The credibility of management relies on its ability to identify and deal with the risks in the most amicable manner.

Evaluation of the risk implies that the management or those in charge must look at the different choices they are faced with and decide on the best way forward in handling the risk. The first step is to define the current problems and identify the alternative, ways of solving the problem. In this regard, while looking at the alternatives, it is important to look at their cost and their likely outcomes. The outcome, in this case, means the monetary value attached to every outcome. The money value may be again or cost. The next step implies the grouping of different uncertainties that may crop up. Their potentials are gauged regarding probabilities.

According to Stingl and Geraldi (2017), the choice of the best alternative is based on judgment. The judgement means a look at the different alternatives on an individual level. The scrutiny of the alternatives gives the manager the best position for judgement because all the alternatives are looked at, and the one that offers the best deal is selected. Crucial factors must be analysed while making a decision. The risks could then be subjected to subjective probability. This means that the decision maker subjects the risk to the probability of occurrence or subjective probability.

Empirical research shows that human sometimes systematically select certain choices. Further, there is evidence that in some cases humans run away from the normally expected utility maximisation maxim that would be an expectation of humanity at any given time. Research in this area has it that humans have certain characteristics while faced with different choices. On the same note, there are certain principles identified: there is a higher likelihood of losses than gains. Secondly, people are more concerned about the variations in their satisfaction (utility) rather than in utter utility. Thirdly, the subjective utility is, as a result, of biases that people possess due to different factors in their daily lives and during deciding to come up with different alternatives and pick the one that best suits (Koleczko, 2012). 
According to Rubinstein (2008), there are different choices. In some cases, certain choices normally give rise to different actions, and the actions have different results at different, give, times. For example, if someone wins the lottery, going on holiday may be one choice, and this would give immediate satisfaction, or one could spend in it on the stock market and have some earnings at a later stage. The question, then, would be; what is the best option of the two. The answer would depend on various factors that are intertwined. For before making a choice, the person would, for example, look at the inflation rates, the expected return from investments, and the level of trust in the stock market and life expectancy of the person. Similarly, while making decisions, sometimes the decisions makers are faced with tough calls because the decisions they make must encompass the likely choices that other people would have made when faced with similar conditions. That gives the basis for the game theory.

In game theory, a single player is pitted against nature. The beliefs that a person has on numerous issues normally indicate and dictate the preferences that one would have given a certain situation. The utility that one derives from various alternatives governs the likelihood of choices being picked. Probability is the most viable root in the determination of chance. New information through Bayes theorem is used to determine the incorporation of new ideas into beliefs. The same theory can be used to elaborate on why and how new belief systems could rise. For example, one's views and attitudes towards a given phenomenon may change over time and shift from the previous position. That change or shift is explained numerous factors that humans encounter in their daily lives.

Stingl and Geraldi (2017) argue that behavioural economics entails the study of how psychological process, social attributes and cognitive realities, and how they influence the economic decisions, in as far as rationality is concerned market conditions are analysed and how people make various decisions. About this school of thought, people have tendencies to behave in certain ways. The first set is framing in, which stereotypes that from the imagination of different people is used to gauge the likely way and manner they would behave, given certain conditions. Heuristics is another understanding in which people make decisions and base them on "rule of thumb" and not on the stern judgment. Market inefficiency is another theme that affects behaviour. In this case, non-rational decision-making processes are discussed together with mispricing (Gigerenzer \& Gaissmaier, 2011).

\section{Human Response and Decision Making}

In most cases, decisions are made based on the conviction of certain events taking place. For example, the winner of an election, the financial market position in the future or the guilt of a suspect in court. The convictions 
arise from subjective probabilities that people attach to them. Research has shown that people base their beliefs on heuristics. However, the reliance on heuristics to form a belief in the occurrence of certain things which normally have realistic explanations can sometimes be compromised since they are vulnerable to error.

According to Bloom (2014), subjective assessment or probability has limited data attached and as such cannot be relied on as having sufficient realistic, tangible backing. An example of subjective probability is the distance of an object from a certain point through the eye of an individual. The individual normally uses the judgement of the eye to approximate and determine the likely position of the distance of the object from the person. In this regard, different individuals looking at the same object from the same vantage point are likely to give different distance measurements. This is because they will use a subjective approach while analysing and ascertaining the reasonable distance of the object from where they are. The data used in the decisions to give direction and distances are based on a heuristic approach and have a great deal of limitation invalidity. For example, different individuals may give different distances based on the clarity of the object to their eyes. Whereas the clarity of the objects may be valid as a means of gauging the distance of the object from the person, it would present error because it could rely on other things as sharpness which may be different among different people. Similarly, while using probability in the case of different judgements, the same levels and kinds of errors could also take place.

Smithson (2015) says different heuristic conditions can be used to describe the different means and ways through which people make judgements. Representativeness is the first example. In this case, people make a judgement in uncertainties by analysing whether certain a variable belongs to another larger group. For example, does $\mathrm{Q}$ belong to the class of $\mathrm{C}$. Availability is another example of heuristic. In this case, the frequencies of certain variables are used to determine the probability of resurfacing in the future.

\section{Conclusion}

This paper has conclusively elaborated that rationality is critical in times of decision making and that rationality is determined by the operating environment and human responses. To prove its case, the paper has described the different concepts that are critical to the subject matter. Furthermore, the paper has used different theories to illustrate its point. The paper has described both rationality theory and the bounded rationality theory. In this regard, the paper has demonstrated that bounded rationality theory offered a fundamental critique of rationality theory. The paper has shown that bounded rationality theory holds that individuals normally have different information on certain 
things; information that should help in formulating responses and decisions. However, in most cases, they may not use all the information to make decisions. In that regard, therefore, heuristics can help in the formulation of the best strategies. For example, the paper has demonstrated that people have habits and methods that they use to do their thing and as such help in the formulation of decisions in their lives.

References:

1. Bendor, J. B. (2010). Bounded rationality and politics. Berkeley: University of California Press.

2. Bloom, N. (2014). Fluctuations in uncertainty. The Journal of Economic Perspectives, 28(2), 153-175.

3. Eusepi, G., \& Hamlin, A. P. (2006). Beyond conventional economics the limits of rational behaviour in political decision making. Cheltenham, UK: Edward Elgar.

4. Farina, F., Hahn, F., \& Vannucci, S. (2006). Ethics, rationality, and economic behaviour. New York: Clarendon Press

5. Giang, P. H. (2015). Decision making under uncertainty comprising complete ignorance and probability. International Journal of Approximate Reasoning, 62, 27-45. doi: http://dx.doi.org/10.1016/j.ijar.2015.05.001

6. Gigerenzer, G., \& Gaissmaier, W. (2011). Heuristic decision making. Annual Review of Psychology, 62(1), 451-482. http://doi:10.1146/annurev-psych-120709-145346

7. He, Z., Yang, L., \& Guan, W. (2014). A Day-to-day Route Choice Model based on Travellers' Behavioural Characteristics. Procedia Social and Behavioral Sciences, 138, 738-747. doi:https://doi.org/10.1016/j.sbspro.2014.07.251

8. Kahneman, D. (2003a). Maps of bounded rationality: Psychology for behavioral economics. The American Economic Review, 93(5), 14491475.

9. Kahneman, D. (2003b). A perspective on judgment and choice: mapping bounded rationality. American Psychologist, 58(9), 697-720. doi: 10.1037/0003-066X.58.9.697

10. Koleczko, K. (2012). Risk and uncertainty in project management and decision making. Public Infrastructure Bulletin, 8 (1), 76-82

11. Pack, S. J., \& Schliesser, E. (2018). Adam Smith, natural movement and physics. Cambridge Journal of Economics, 42(2), 505-521. doi:10.1093/cje/bex008

12. Phillips, P. J., \& Pohl, G. (2014). Prospect theory and terrorist choice. Journal of Applied Economics, 17(1), 139-160. doi: http://dx.doi.org/10.1016/S1514-0326(14)60006-4 
13. Rubinstein, A. (2008). Modeling bounded rationality. Cambridge, Mass: MIT Press.

14. Smithson, M. (2015). Probability judgments under ambiguity and conflict. Frontiers in Psychology, 6, 674.

15. Stingl, V., \& Geraldi, J. (2017). Errors, lies and misunderstandings: Systematic review on behavioural decision making in projects. International Journal of Project Management, 35(2), 121-135. doi: http://doi.org/10.1016/j.ijproman.2016.10.009

16. Vlaev, I. (2018). Local Choices: Rationality and the Contextuality of Decision-Making. Brain sciences,

$8(1)$

8. doi:10.3390/brainsci8010008

17. Walker, D. H. T., Davis, P. R., \& Stevenson, A. (2017). Coping with uncertainty and ambiguity through team collaboration in infrastructure projects. International Journal of Project Management, 35(2), 180190. doi: http://dx.doi.org/10.1016/j.ijproman.2016.11.001

18. Weyland, K. G. (2006). Bounded rationality and policy diffusion social sector reform in Latin America. Princeton, N.J.: Princeton University Press.

19. Wu, G., Liu, C., Zhao, X., \& Zuo, J. (2017). Investigating the relationship between communication-conflict interaction and project success among construction project teams. International Journal of Project Management, 35(8),

1466-1482. doi:https://doi.org/10.1016/j.ijproman.2017.08.006 